\title{
Mobile Phones and/ or Smartphones and Their Use in the Management of Dementia - Findings from the Research Studies
}

\author{
Blanka Klimova \\ University of Hradec Kralove, Rokitanskeho 62, Hradec Kralove, Czech Republic \\ blanka.klimova@uhk. cz
}

\begin{abstract}
At present, there is a significant increase in the number of older population groups worldwide. This accelerating trend in the rise of older population groups inevitably results in serious economic and social changes accompanied with a number of aging diseases such as dementia. The purpose of this review study is to explore the use of mobile phones and/ or smartphones and their benefits and limitations for patients with dementia. The methods include a literature review of available studies on this topic found in Web of Science, Science Direct, and MEDLINE, and a method of comparison and evaluation of their findings. The results of this article show that the use of mobile phones and/ or smartphones by patients with dementia can provide support for the activities of daily life. In addition, they can reduce both mental and economic burden of their caregivers and help doctors in their assessments and diagnoses. Nevertheless, more original research studies, especially in the area of the effectiveness of their use should be conducted. The same is true for sustainable support in the use of mobile phones by patients with dementia.
\end{abstract}

Keywords: mobile phones; smartphones; dementia; patients; benefits; limitations

\section{Introduction}

Currently, there is a growing number of older population groups worldwide. For instance, in Europe older people aged 55+ years represent $25 \%$ of the whole population [1]. This accelerating trend in the rise of older population groups inevitably results in serious economic and social changes accompanied with a number of aging diseases such as dementia.

Dementia, respectively Alzheimer's disease, together with heart diseases, cancer, and respiratory diseases, is one of the most common causes of death among older people. [2] Nowadays, dementia affects approximately 58 million people and it is estimated that this number of older people with dementia should triple by 2050 since each year there are about 9.9 million of new dementia cases worldwide. [3-4] The key symptom of dementia is cognitive decline. Unfortunately, at the moment, there is no effective pharmacological treatment for this cognitive decline. [5] Thus, there is an increasing interest in non-pharmacological alternative approaches which may maintain or in some cases even improve the quality of life of people living with dementia.

adfa, p. 1, 2011.

(C) Springer-Verlag Berlin Heidelberg 2011 
And mobile devices appear to offer some benefits for enhancing the quality of life of these people, especially enabling them to stay independent and socially engaged in the early phases of this disease. [6]

The purpose of this review study is to explore the use of mobile phones and/ or smartphones and their benefits and limitations for patients with dementia.

\section{Methods}

The methods of this review involve a method of literature review of available research studies found on the use of mobile phones and/ or smartphones in dementia in the world's databases Web of Science, Science Direct, and MEDLINE, and a method of comparison and evaluation of the findings from the detected studies. The search words were mobile phone use AND dementia, mobile phone use AND Alzheimer's disease, smartphone use AND dementia, smartphone use AND Alzheimer's disease.

Although the use of mobile phones is not that ubiquitous among patients with dementia, their use is moderately rising as it can been seen from the number of publications recorded on this topic in Science Direct from 2000 till 2016 (consult Fig. 1 below).

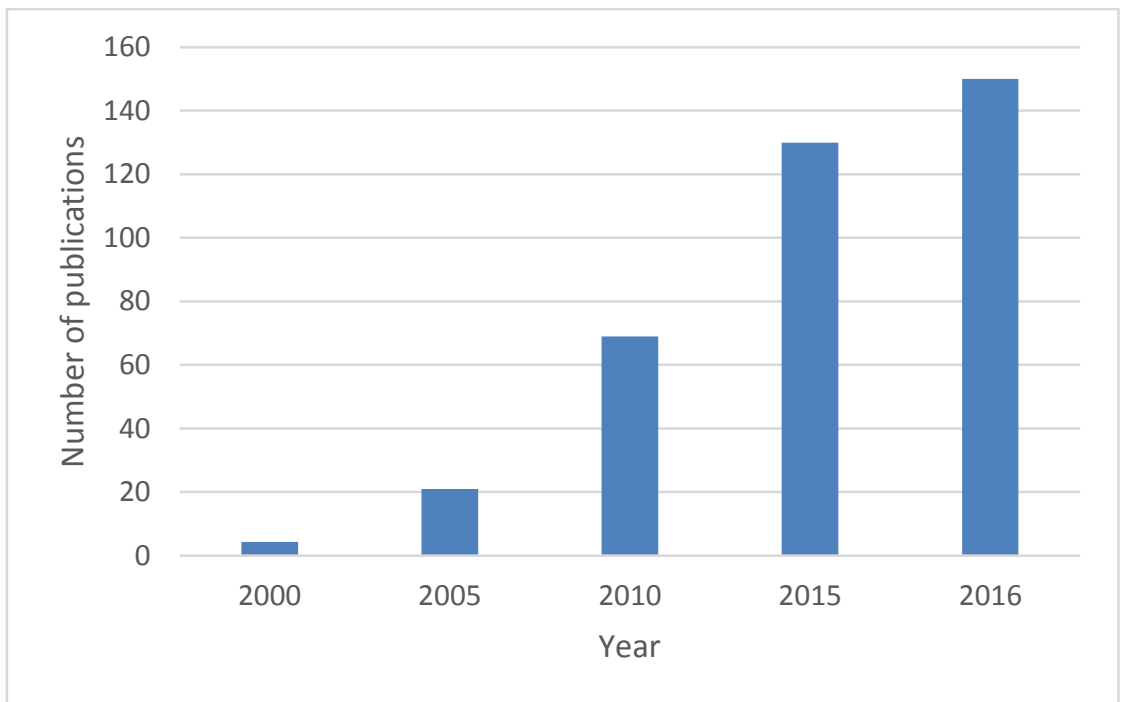

Fig. 1. A number of publications on the topic of mobile phone use in dementia from 2000 till 2016, based on the data from Science Direct [7] - author's own processing

\section{$3 \quad$ Findings and their discussion}

On the basis of literature review, the research studies concerning the use of mobile phones and/ or smartphones by patients with dementia can be divided into several areas according to their focus as follows: 
- studies concentrating on the adoption and usability of these devices by patients with dementia; [6, 8-11]

- descriptive studies depicting the development of potential mobile phone/ smartphone apps for patients with dementia; [12-13]

- studies exploring the role of these mobile devices for the assessment and diagnostic purposes; [14-16]

- studies focusing on the actual use of mobile phones and/ or smartphones by patients with dementia. [17-19]

Thorpe et al. [6] explored the adoption of smartphone and smartwatch use among people with mild dementia. In their study they discovered that the smartphone should be used for input and smartwatch for output, e.g., notifications, orientation and behavior sensing. The most appreciated function by patients was scheduling which reminded or notified them about the activities they should perform. The navigation or emergency support functions were not considered to be that much useful. The most important aspect for patients with dementia was personalization of both devices, i.e., tailoring the devices to their individual needs. This was in fact confirmed in other research studies as well. For example, Faucounau et al. [19] claim that it is a must to involve end-users in the co-design of new technologies in order to develop tailored devices. Furthermore, Hedman et al. [10] on the amount and type of everyday technology use found out that people with cognitive impairment tended to decrease the use of everyday technology over time. This is quite common since patients with dementia are generally older people and they like to use what they already know. Therefore higher awareness of the benefits of these devices should be raised among patients and their caregivers.

In addition, mobile phones and/ or smartphones have big potential in the assessment and diagnosis of dementia for the following reasons: [20]

- they have an ability to accurately record and measure the outcomes without manual operation;

- they can minimize the examiner's biases;

- they enable older people to remain independent in their tasks of daily living;

- they enable older people to understand conditions as well as terms and symptoms associated with their conditions from credible sources;

- they are cost-effective; they cut potential costs on treatment and hospitalization of older people;

- they can provide enhance access to healthcare for older people in remote areas;

- they target to improve the overall quality of life of older individuals; and

- they are ecological.

For instance, Sangha et al. [15] in their research study showed that before the introduction of the smartphone app for cognitive assessment, only $36 \%$ of the patients over 75 years old had been assessed cognitively. After the introduction the smartphone app, the percentage of cognitive assessments improved to 63\%. The findings of the study also revealed that the improvements in cognitive assessments had been most marked after individual teaching of the doctors on the wards in the use of the app and on making the app available on the ward tablets. 
As far as the actual use of both devices is concerned, the most exploited applications according to the research findings seem to be reminders and tracking/ positioning applications. [6, 13, 18-19] Table 1 below then summarizes the key benefits and limitations of the use of mobile phones and/ or smartphones for patients with dementia.

Table 1. Benefits and limitations of the use of mobile phones and/ or smartphones in the management of dementia

\begin{tabular}{|c|c|}
\hline Benefits & Limitations \\
\hline $\begin{array}{l}\text { - potential cost savings of } \\
\text { care, reduced mental bur- } \\
\text { den for patient's caregiver; }\end{array}$ & $\begin{array}{l}\text { - not sufficient access to these } \\
\text { devices; }\end{array}$ \\
\hline $\begin{array}{l}\text { - activities of daily life be- } \\
\text { come easier, which can } \\
\text { lead to an improved quality } \\
\text { of life for users and a re- } \\
\text { duced need for help from } \\
\text { society and relatives; }\end{array}$ & $\begin{array}{l}\text { - more evidence on the effica- } \\
\text { cy of technologies is re- } \\
\text { quired to improve cover- } \\
\text { age of these devices for pa- } \\
\text { tients with dementia by in- } \\
\text { surance companies; }\end{array}$ \\
\hline $\begin{array}{l}\text { - patients and caregivers are } \\
\text { positive and motivated to } \\
\text { use technologies in the fu- } \\
\text { ture; }\end{array}$ & $\begin{array}{l}\text { - unexpected ethical, as well } \\
\text { as environmental and } \\
\text { health consequences of } \\
\text { new technologies used in } \\
\text { medicine; }\end{array}$ \\
\hline $\begin{array}{l}\text { - provide patients with safety } \\
\text { and security; }\end{array}$ & $\begin{array}{l}\text { - improved knowledge and } \\
\text { awareness } \\
\text { - of the benefits of these de- } \\
\text { vices are } \\
\text { - needed. }\end{array}$ \\
\hline $\begin{array}{l}\text { - offer opportunities for early } \\
\text { assessment and diagnosis } \\
\text { of dementia. }\end{array}$ & \\
\hline
\end{tabular}

Source: author's own processing

\section{Conclusion}

The results of this article show that the use of mobile phones and/ or smartphones by patients with dementia can provide support for their activities of daily life. In addition, they can reduce both mental and economic burden of their caregivers and help doctors in their assessments and diagnoses. Nevertheless, more original research studies, especially in the area of the effectiveness of their use should be conducted. The same is true for sustainable support in the use of mobile phones by patients with dementia.

\section{Acknowledgments}


This article is supported by SPEV project 2017/2018 run at the Faculty of Informatics and Management, University of Hradec Kralove, Czech Republic. The author especially thanks Josef Toman for his help with data compilation.

\section{References}

1. Global AgeWatch index 2015: Insight report. http://www.population.gov.za/index.php/npu-articles/send/22-aging/535-global-agewatchindex-2015-insight-report. (2015)

2. Vann, M.R., Bass, P.F. The 15 most common health concerns for seniors. http://www.everydayhealth.com/news/most-common-health-concerns-seniors/. (2016)

3. Langa, K.M. Is the risk of Alzheimer's disease and dementia declining? Alzheimer's Research \& Therapy, vol. 7, pp. 1-4. (2015)

4. WHO. http://www.who.int/features/factfiles/dementia/en/. (2016)

5. Karakaya, T., Fußer, F., Schroder, J., Pantel, J. Pharmacological treatment of mild cognitive impairment as a prodromal syndrome of Alzheimer's disease, Current Neuropharmacology, vol. 11, no. 1, p. 102. (2013)

6. Thorpe, J.R., Ronn-Andersen, K.V., Bien, P., Ozkil, A.G., Forchhammer, B.H., Maier, A.M. Pervasive assistive technology for people with dementia: A UCD case, Healthc Technol Lett, vol. 3, no. 4, pp. 297-302. (2016)

7. Science Direct. http://www.sciencedirect.com/science?_ob=ArticleListURL\&_method=list\&_ArticleListI $\mathrm{D}=-$ $1198558763 \&$ _sort=r\&_st=13\&view=c\&md5=9c87fb919562daeed92c5141e26d971e \&sea rchtype=a. (2017)

8. Hartin, P.J., Nugent, C.D., McClean, S.I., Cleland, I., Norton, M.C., Sanders, C., Tschanz, J.T. A smartphone application to evaluate technology adoption and usage in persons with dementia, Conf Proc IEEE Eng Med Biol Soc, vol. 2014, pp. 5389-92. (2014)

9. van Osch, M., Rovekamp, A., Bergman-Agteres, S.N., Wijsman, L.W., Ooms, S.J., Mooijaart, S.P., Vermeulen, J. User preferences and usability of iVitality: Optimizing an innovative online research platform for home-based health monitoring, Patient Prefer Adherence, vol. 9, pp. 857-867. (2015)

10. Hedman, A., Nygard, L., Almkvist, O., Kottorp, A. Amount and type of everyday technology use over time in older adults with cognitive impairment, Scand J Occup Ther. Vol. 22, no. 3, pp. 196-206. (2015)

11. Malinowsky, C., Nygard, L., Kottorp, A. Using a screening tool to evaluate potential use of e-health services for older people with and without cognitive impairment, Aging Ment Health, vol. 18, no. 3, pp. 340-345. (2014)

12. Weir, A.J., Paterson, C.A., Tieges, Z., MacLullich, A.M., Parra-Rodriguez, M., Della Sala, S., Logie, R.H. Development of Android apps for cognitive assessment of dementia and delirium, Conf Proc IEEE Eng Med Biol Soc, vol. 2014, pp. 2169-2172. (2014)

13. McKinstry, B., Sheikh, A. The use of global positioning systems in promoting safer walking for people with dementia, J Telemed Telecare, vol. 19, no. 5, pp. 288-292. (2013)

14. Leurent, C., Ehlers, M.D. Digital technologies for cognitive assessment to accelerate drug development in Alzheimer's disease, Clin Pharmacol Ther. vol. 98, no. 5, pp. 475-476. (2015) 
15. Sangha, S., George, J., Winthrop, C., Panchal, S. Confusion: delirium and dementia - a smartphone app to improve cognitive assessment, BMJ Qual Improv Rep, vol. 4, no. 1, pp. pii: u202580.w1592. (2015)

16. Brouillette, R.M., Foil, H., Fontenot, S., Correro, A., Allen, R., Martin, C.K., BruceKeller, A.J., Keller, J.N. Feasibility, reliability, and validity of a smartphone based application for the assessment of cognitive function in the elderly, PLoS One, vol. 8, no. 6, p. e65925. (2013)

17. Hartin, P.J., Nugent, C.D., McClean, S.I., Cleland, I., Tschanz, J.T., Clark, C.J., Norton, M.C. The empowering role of mobile apps in behavior change interventions: The gray matters randomized controlled trial, JMIR Mhealth Uhealth, vol.4, no. 3, p. e93. (2016)

18. Olsson, A., Engstrom, M., Lampic, C., Skovdahl, K. A passive positioning alarm used by persons with dementia and their spouses--a qualitative intervention study, BMC Geriatr, vol. 13, p. 11. (2013)

19. Faucounau, V., Riguet, M., Orvoen, G., Lacombe, A., Rialle, V., Extra, J., Rigaud, A.S. Electronic tracking system and wandering in Alzheimer's disease: A case study, Ann Phys Rehabil Med, vol. 52, no. 7-8, pp. 579-587. (2009)

20. Klimova, B., Valis, M., Kuca, K. Potential of mobile technologies and applications in the detection of mild cognitive impairment among older generation groups, Soc Work Health Care, pp. 1-12, doi: 10.1080/00981389.2017.1316339. (2017) 